a partial depolarisation of light would give a similar effect. We have therefore determined directly the amplitude of magnetorotation for a high frequency magnetic field using the following procedure. Polarised light passes first through a tube containing a liquid, such as benzene, which gives the usual diamag. netic rotation, and then through a nicol at $45^{\circ}$ with respect to the first. The tube is placed on the axis of the coil supplying the magnetic field. The small magnetic rotation causes a very feeble periodic variation of the intensity of light, which is superimposed on the continuous intensity. The beam then falls on a photoelectric cell connected to a powerful resonance amplifier, the imput circuit of which is tuned to that of the magnetic field. Only the very slight modulation of the photoelectric current is amplified, whilst the great intensity of the continuous light does not affect the readings of the compensated microammeter in the output circuit.

As the amplification depends to a large extent on the frequency, an optical calibration method has been developed, using as source of light a Kerr cell with a definite alternating potential on its plates. The magnetic field frequencies ranged from 0.15 to $4.0 \times 10^{8}$ c.p.s., whilst the peak values of the magnetic field employed were 0.97 and 0.29 gauss, the corresponding maximum Larmor frequencies being $1 \cdot 36$ and $0.49 \times 10^{6}$ respectively. Within experimental error, no diminution of rotation was observed when the frequency $n$ exceeded the Larmor frequency $O_{L}$. EGON BRETSCHER.

Physikalisches Institut der

Eidg. Techn. Hochschule, Zürich.

${ }^{1}$ Bretscher and Deck, Helv. Phys. Acta, 6, 229; 1933.

\section{Paper Hygrometers}

Dr. Grant and Mr. Mellanby ${ }^{1,2}$ have commented on the different periods required for paper to attain stretch equilibrium when this property is being used for hygrometric measurement. The following curve (Fig. 1) which is included in the paper quoted under

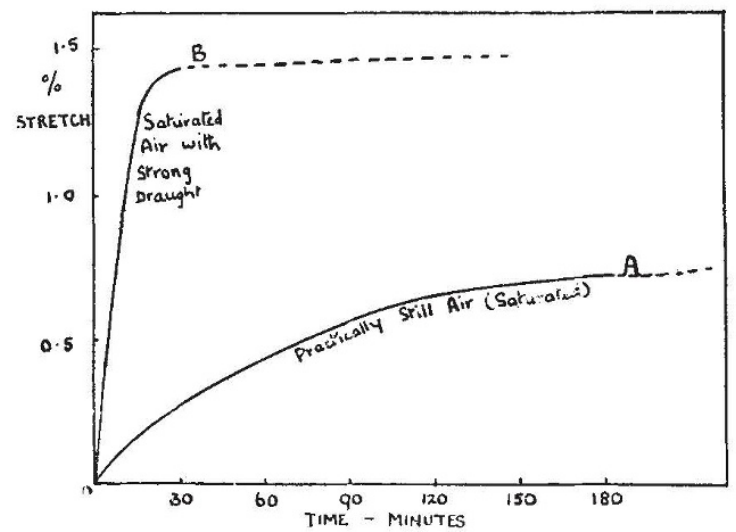

Fia. 1. Rate of attaining stretch equilibrium.

my name by Dr. Grant, may throw some light on the difficulty.

It will be seen that air velocity has a very great effect and that in comparatively still air the rate of change, after an initial period, may become so small that conditions resemble those of equilibrium.
The paper used in this case was a rosin sized mixed wood furnish and rather thicker than those advocated by Dr. Grant, being $100 \mathrm{gm} . / \mathrm{sq}$. m., but nevertheless the air velocity factor should be carefully watched.

Research Laboratory,

Aylesford Paper Mills. Oct. 30 .

NatURe, 132, 66, July $8,1933$.

- NATURE, 132, 677, Oct. 28, 1933.

IN connexion with Dr. J. Grant's letter ${ }^{1}$, on paper hygrometers, some experiments made some months ago on an experimental paper-operated indicating hygrometer may be of interest. The instrument, in aspect similar to the 'Edney' paper-metal hygrometer, was made by causing two pieces of the same paper to adhere together, the grain of one being at right angles to that of the other. A light pointer attached to the free end of a strip of this double paper indicated the movement as the strip curled due to differential expansion.

This instrument gave quite good results provided extreme humidity was not encountered, but if one attempted to calibrate at 100 per cent R.H., then the other scale points always moved to different positions. Probably cyclic 'ageing' would provide reliable movements.

Very rapid initial indication was obtained with this instrument, but final steady values could only be obtained after ten or fifteen minutes, even using very thin Japanese rice paper. It was mainly for this reason that further experiments were abandoned, and also because it was found that until the case had reached the air temperature of a fresh atmosphere, discrepancies resulted due to the slight warming or cooling of the air which was operating the element as it passed through the case.

G. R. R. BRAY

(Chief of Electrical Laboratory). The British Thomson-Houston Co., Ltd., Rugby. Nov. 6.

1 Nature, 132, 677, Oet. 28, 1933.

\section{$\mathrm{X}$-Ray Investigation of Tridymite-glass}

There has been a lengthy controversy between G. W. Morey ${ }^{1}$ and A. Dietzel ${ }^{2}$ concerning the nature of the crystallites in devitrified glass in region $B$ of the phase diagram of the system : $\mathrm{SiO}_{2} \mathrm{Na}_{2} \mathrm{O} \mathrm{CaO}$ (see ${ }^{2}$ ). Morey, from microscopic investigations, thought that tridymite was present in this devitrified glass, whereas Dietzel, with the further help of expansion curves, decided in favour of cristobalite. Microscopic work on such a problem is very difficult, especially when dealing with crystallites incrusted in a vitreous mass. On the other hand, expansion curves are quite useless. There are three anomalies in the expansion of pure tridymite. The first occurs about $120^{\circ} \mathrm{C}$., the second around $165^{\circ} \mathrm{C}$. and the last at $420^{\circ} \mathrm{C}$. A solid rod of $36 \mathrm{~mm}$. of glass $B$ does not give any appreciable anomaly of expansion. A rod of the same dimensions made from a powder of this devitrified glass also gives a negative result. $\mathrm{X}$-ray powder analysis on the contrary gives a definite solution of the problem. A devitrified glass of the initial percentage composition: $\mathrm{SiO}_{2} 78$, $\mathrm{CaO} 12$, and $\mathrm{Na}_{2} \mathrm{O} 10$ (glass $B$ ) gives an unmistakable pattern of tridymite (Co-K $\alpha-50$ m.a.h.). 